CLINICAL STUDY

\title{
Hemostasis and fibrinolysis in non-diabetic overweight and obese men and women. Is there still a role for leptin?
}

\author{
Ilse Mertens ${ }^{1}$, Robert V Considine ${ }^{3}$, Marc Van der Planken ${ }^{2}$ and Luc F Van Gaal ${ }^{1}$ \\ ${ }^{1}$ Department of Diabetology, Metabolism and Clinical Nutrition and ${ }^{2}$ Laboratory of Hematology and Hemostasis, Faculty of Medicine, Antwerp University \\ Hospital, University of Antwerp (UA), Antwerp, Belgium and ${ }^{3}$ Division of Endocrinology and Metabolism, Indiana University School of Medicine, \\ Indianapolis, USA \\ (Correspondence should be addressed to L F Van Gaal; Email: luc.van.gaal@uza.be)
}

\begin{abstract}
Objective: Leptin has been associated with disturbances in hemostasis and fibrinolysis, with inconsistent results on the influence of fat mass. However, the influence of the amount of visceral adipose tissue (VAT) and abdominal subcutaneous adipose tissue (SAT) has not yet been studied. In this study, we investigated the relationship between leptin and fibrinogen, von Willebrand factor antigen (vWF:Ag), and plasminogen-activator inhibitor-1 (PAI-1) activity and determined the influence of associated metabolic variables and VAT versus SAT.

Methods: Fibrinogen, vWF:Ag, PAI-1,VAT and SAT (CT-scan), and insulin resistance (homeostasis model assessment; HOMA-IR) were measured in 199 women and 81 men with overweight or obesity visiting the weight management clinic of a university hospital.

Results: Leptin did not relate to fibrinogen $(r=0.11$ and 0.13 in women and men respectively; $P>0.05)$, a relationship with vWF:Ag was only found in men $(r=0.31 ; P=0.005)$, while leptin related to PAI-1 activity in both men $(r=0.36 ; P<0.001)$ and women $(r=0.23 ; P<0.001)$. Further analysis showed leptin to have an effect on the variation of PAI-1 independent of VAT and HOMA-IR in women, but not in men. Multiple regression showed HOMA-IR to be the most important determinant of PAI-1, both in men and women, but leptin also showed an independent effect. As for vWF:Ag, leptin was an independent determinant in men only.

Conclusions: PAI-1 related to leptin levels independent of fat mass percentage, HOMA-IR, and the amount of VAT and SAT. For vWF:Ag this relationship was found only in men, and not in women, while a relationship with fibrinogen could not be demonstrated.
\end{abstract}

European Journal of Endocrinology 155 477-484

\section{Introduction}

Obesity has been shown to be associated with an increased incidence of cardiovascular morbidity and mortality (1). However, the exact mechanisms linking an increased amount of adipose tissue mass to cardiovascular disease are not yet completely clear. Until about a decade ago, adipose tissue was considered as a passive tissue for the storage of excess energy. This changed with the discovery of leptin (2) showing adipose tissue to be an important endocrine organ, secreting a variety of bioactive substances, such as leptin and plasminogen activator inhibitor-1 (PAI-1) $(2,3)$. Although initially thought to be merely involved in the regulation of energy homeostasis, leptin has been found to influence different cardiovascular processes, such as platelet aggregation, angiogenesis, and oxidative stress (4). Consistent with these findings, reports from the MONICA (5) and WOSCOPS (6) cohorts have shown a relationship between leptin levels and cardiovascular disease. In contrast, the Quebec Cardiovascular study could not show an association (7) and a recent preliminary study from our group (8) even showed a potential protective effect of leptin on coronary heart disease in patients with type-2 diabetes. The latter study was the only one correcting for the exact amount of abdominal subcutaneous adipose tissue (SAT), which has been shown to be important in the determination of leptin levels $(9,10)$. Obesity and an increased amount of adipose tissue have also been associated with an increase in prothrombotic factors, such as fibrinogen and von Willebrand factor antigen (vWF:Ag), and a decrease in fibrinolytic activity due to raised levels of its main inhibitor PAI-1 (11). Several studies investigated the relationship between leptin and factors of the hemostatic and fibrinolytic system, and found the relation to be independent $(5,12-15)$ or dependent (16-20) on the amount of fat mass and/or insulin resistance. Although potentially important in the relationship between leptin and hemostatic and fibrinolytic factors, none of these studies investigated the additional role of the amount of visceral adipose tissue 
(VAT) versus SAT. In this study we wanted to investigate the relationship between leptin and fibrinogen, vWF:Ag, and PAI-1, as representatives of the hemostatic and fibrinolytic system, and to determine whether the observed relationships were independent of associated metabolic variables and the amount of VAT and/or SAT as measured with CT-scan.

\section{Subjects and methods}

\section{Subjects}

The subject characteristics are shown in Table 1. The study population consisted of 199 women (154 pre- and 45 postmenopausal) and 81 men: 44 subjects were overweight $\left(\mathrm{BMI} \geqq 25.0-29.9 \mathrm{~kg} / \mathrm{m}^{2}\right)$ and 236 were obese $\left(\mathrm{BMI} \geqq 30 \mathrm{~kg} / \mathrm{m}^{2}\right)$. The subjects were selected in chronological order from the outpatient clinic and did not participate in a structured weight-loss program at the time of enrolment. They were 18 years or older and medication influencing coagulation, such as oral anticonceptives, hormonal replacement therapy, anticoagulants, platelet inhibitors, acetyl-salicyl-acid derivatives, non-steroidal antiinflammatory drugs, and recent antibiotic use were not allowed. Other exclusion criteria were Cushing's disease, thyroid illness (TSH $>4$ or $<0.1 \mu \mathrm{U} / \mathrm{ml})$, manifest hypertriglyceridemia $(>4.52 \mathrm{mmol} / \mathrm{l})$, treated or newly diagnosed diabetes, and acute illness. Patients were clinically examined by a physician and shown to be in generally good health. This study was approved by the ethical committee of the Antwerp University Hospital and all patients gave their informed consent. Comparing pre- and postmenopausal women, after adjustment for age, no significant differences were found in the levels of fibrinogen $(P=0.810)$, vWF:Ag $(P=0.064)$ or PAI-1 $(P=0.326)$ with a trend towards higher levels of leptin $(P=0.051)$ in postmenopausal women. Data on smoking habits were available in 185 women and 74 men. In the female subgroup, 119 women were smokers, 21 were former smokers and 45 were non-smokers. In the male subgroup, 22 were smokers, 22 were former smokers and 30 were non-smokers. In men and women, smokers were compared with non-smokers separately. Although fibrinogen levels were higher in smokers compared with non-smokers both in women $(356 \pm 79$ vs $338 \pm 61 \mathrm{mg} /$ $\mathrm{dl} ; P=0.153)$ and men $(349 \pm 78$ vs $324 \pm 80 \mathrm{mg} / \mathrm{dl}$; $P=0.261)$, these differences were not statistically significant. In women and men, no significant differences were found between smokers and non-smokers in the levels of vWF:Ag (161 \pm 54 vs $169 \pm 76 \% ; P=0.854$ and $164 \pm 56$ vs $145 \pm 52 \% ; P=0.223$ respectively), PAI-1 (15.6 \pm 9.3 vs $16.7 \pm 9.4 \mathrm{AU} / \mathrm{ml} ; P=0.508$ and $22.0 \pm 9.6$ vs $20.1 \pm 9.9 \mathrm{AU} / \mathrm{ml} ; P=0.504$ respectively) or leptin $(26.2 \pm 14.3$ vs $30.5 \pm 17.2 \mathrm{ng} / \mathrm{ml} ; P=0.112$ and $17.7 \pm 9.1$ vs $15.7 \pm 11.5 \mathrm{ng} / \mathrm{ml} ; \quad P=0.506$ respectively).

\section{Anthropometric measurements}

All measurements were performed in the morning, with patients in fasting conditions and undressed. Height was measured to the nearest $0.5 \mathrm{~cm}$ and body weight with a digital scale to the nearest $0.1 \mathrm{~kg}$. Body mass index (BMI) was calculated as weight in kilograms over height in meters squared. The waist circumference was

Table 1 Subject characteristics. Data are presented as mean \pm S.D. (range).

\begin{tabular}{|c|c|c|}
\hline & Women $(n=199)$ & Men $(n=81)$ \\
\hline Age (years) & $41 \pm 12(18-73)$ & $41 \pm 11(18-66)$ \\
\hline BMI $\left(\mathrm{kg} / \mathrm{m}^{2}\right)$ & $35.9 \pm 6.9(25.1-64.1)$ & $37.7 \pm 6.3(26.5-52.1)^{*}$ \\
\hline Waist $(\mathrm{cm})$ & $107.0 \pm 16.5(78.0-150.0)$ & $122.0 \pm 14.5(90.5-158.0)^{\dagger}$ \\
\hline Hip (cm) & $117.0 \pm 11.0(85.0-144.0)$ & $114.0 \pm 11.0(91.0-144.0)^{*}$ \\
\hline WHR & $0.91 \pm 0.13(0.68-1.31)$ & $1.07 \pm 0.11(0.85-1.34)^{f}$ \\
\hline Fat mass (\%) & $49.3 \pm 6.8(26.1-64.8)$ & $41.4 \pm 7.2(27.3-56.5)^{\dagger}$ \\
\hline VAT $\left(\mathrm{cm}^{2}\right)$ & $149 \pm 73(28-392)$ & $226 \pm 90(44-469)^{\dagger}$ \\
\hline $\mathrm{SAT}\left(\mathrm{cm}^{2}\right)$ & $553 \pm 142(105-878)$ & $519 \pm 155(249-868)$ \\
\hline Visceral/subcutaneous ratio & $0.28 \pm 0.13(0.05-1.01)$ & $0.46 \pm 0.24(0.11-1.59)^{\dagger}$ \\
\hline Total cholesterol (mmol/l) & $5.51 \pm 0.96(3.11-8.42)$ & $5.56 \pm 0.90(3.52-7.85)$ \\
\hline HDL cholesterol (mmol/l' & $1.39 \pm 0.39(0.67-2.98)$ & $1.08 \pm 0.29(0.44-2.31)^{\dagger}$ \\
\hline Triglycerides (mmol/l) & $1.42 \pm 0.71(0.42-3.89)$ & $1.99 \pm 0.96(0.56-4.27)^{\dagger}$ \\
\hline Fasting glucose (mmol/l) & $4.7 \pm 0.5(3.6-6.9)$ & $4.9 \pm 0.6(3.7-6.9)^{\star}$ \\
\hline Fasting insulin $(\mathrm{mU} / \mathrm{l})$ & $17.6 \pm 9.4(1.4-54.0)$ & $22.5 \pm 13.5(2.4-83.0)^{\ddagger}$ \\
\hline Fibrinogen (mg/dl) & $343 \pm 67(188-536)$ & $333 \pm 76(203-597)$ \\
\hline vWF:Ag (\%) & $167 \pm 11(59-541)$ & $161 \pm 58(62-401)$ \\
\hline PAl-1 (AU/ml) & $16.9 \pm 9.2(0.8-38.6)$ & $20.9 \pm 9.7(2.0-37.3)^{\dagger}$ \\
\hline Leptin (ng/ml) & $29.5 \pm 16.9(3.4-97.6)$ & $16.4 \pm 11.3(1.4-66.5)^{\dagger}$ \\
\hline
\end{tabular}

BMI, body mass index; WHR, waist-to-hip ratio; TAT, total adipose tissue; VAT, visceral adipose tissue; SAT, subcutaneous adipose tissue; HDL, high density lipoprotein; HOMA-IR, homeostatic model assessment of insulin resistance; vWF: Ag, non Willebrand factor antigen; PAI-1, plasminogen activator inhibitor-1. Differences between women and men: ${ }^{\star} P \leq 0.05 ;{ }^{\dagger} P \leq 0.001 ;{ }^{\ddagger} P \leq 0.01$. 
measured at the mid-level between the lower rib margin and the iliac crest. Hip circumference was measured at the level of the trochanter major and the waist-to-hip ratio (WHR) was calculated. Body composition was determined by bio-impedance analysis as described by Lukaski et al. (21), and fat mass percentage was calculated, using the formula of Deurenberg et al. (22). A CT-scan at L4-L5 level was performed to measure the amount of total adipose tissue (TAT), VAT, and abdominal SAT according to the methods described previously (23).

\section{Laboratory analyses}

A fasting blood sample was taken from an antecubital vein between 0800 and $1000 \mathrm{~h}$ to determine the fasting levels of leptin, total and high density lipoprotein (HDL) cholesterol, and triglycerides. For assay of fibrinogen, vWF:Ag and PAI-1 activity, blood was collected without stasis. A minimal oral glucose tolerance test (OGTT) was performed with $75 \mathrm{~g}$ glucose, with blood samples taken to determine glucose and insulin in the fasted state and $2 \mathrm{~h}$ after the glucose load. Diabetes was diagnosed based on the OGTT data according to the WHO criteria (24). Insulin resistance was estimated using the homeostasis model assessment of insulin resistance (HOMA-IR) as described by Matthews et al. (25) and calculated as (insulin (mU/ l) $\times$ glucose $(\mathrm{mmol} / \mathrm{l})) / 22.5$, with a reference value for normal insulin sensitivity as 1 . Plasma glucose, total cholesterol, and triglycerides were measured using Vitros 750 XRC (Ortho Clinical Diagnostics, Johnson \& Johnson, USA). HDL cholesterol was measured using Hitachi 912 (Roche Diagnostics). Insulin levels were measured with the Medgenix two-site IRMA (BioSource, Nivelles, Belgium). Estradiol was measured with RIA (DiaSorin Saluggia, Italy). FSH and TSH were measured using Vitros Immunodiagnostic Products (Ortho Clinical Diagnostics, Johnson \& Johnson, USA). Prolactin levels were measured with the AutoDelfia Automatic Immunoassay System (AutoDelfia, Wallac, Finland). Leukocyte count was measured on ADVIA 120 (Bayer, US; normal range: $4.3-10.0) \times 10^{9} / \mathrm{l}$, fibrinogen was assayed with a Clauss-Vermylen-based thrombinclotting assay with the STA-fibrinogen reagents on an STA-analyser (Diagnostic, Stago, France; normal range: $200-400 \mathrm{mg} / \mathrm{dl}$ ). vWF:Ag was measured using an ELISA technique (Asserachrom, Stago, France; normal range: $60-160 \%$ ). PAI-1 activity (expressed as $\mathrm{AU} / \mathrm{ml}$ ) was measured using a chromogen substrate method (Coatest, Chromogenix, Sweden; normal range: 5-15 AU/ml). Serum leptin was measured with an, as RIA described previously (26).

\section{Statistical analyses}

Statistical calculations were performed using the statistical package SPSS version 12.0 (SPSS, Chicago, IL, USA). Normality of distribution was verified with a Kolmogorov-Smirnov test, for women and men separately. Variables that were not normally distributed were $\log$ transformed. Partial correlation coefficients were calculated to control for influencing factors. Differences in continuous variables were tested with Student's $t$ test. A $2 \times 2$ ANOVA was used to determine the influence of leptin, VAT, SAT, and HOMA-IR on the variation of PAI-1 activity. Linear regression analyses with studentized residuals were used to test whether differences were independent of influencing factors. In order to determine the most important determinants of PAI-1 activity, a stepwise multiple regression analysis, with PAI-1 activity as the dependent variable, was performed. The results were considered significant when $P<0.05$.

Table 2 Pearson correlation coefficients with anthropometric and metabolic variables.

\begin{tabular}{|c|c|c|c|c|c|c|c|c|}
\hline & \multicolumn{4}{|c|}{ Women $(n=199)$} & \multicolumn{4}{|c|}{ Men $(n=81)$} \\
\hline & $\begin{array}{l}\text { Fibrinogen } \\
\text { (mg/dl) }\end{array}$ & $\begin{array}{c}\text { VWF:Ag } \\
(\%)\end{array}$ & $\begin{array}{c}\text { PAl-1 } \\
\text { (AU/ml) }\end{array}$ & $\begin{array}{l}\text { Leptin } \\
\text { (ng/ml) }\end{array}$ & $\begin{array}{c}\text { Fibrinogen } \\
\text { (mg/dl) }\end{array}$ & $\begin{array}{c}\text { VWF:Ag } \\
(\%)\end{array}$ & $\begin{array}{c}\text { PAl-1 } \\
\text { (AU/ml) }\end{array}$ & $\begin{array}{l}\text { Leptin } \\
\text { (ng/ml) }\end{array}$ \\
\hline BMI $\left(\mathrm{kg} / \mathrm{m}^{2}\right)$ & $0.39^{*}$ & $0.14^{\dagger}$ & $0.25^{\star}$ & $0.37^{\star}$ & $0.24^{\dagger}$ & 0.21 & $0.32^{\ddagger}$ & $0.60^{*}$ \\
\hline Waist (cm) & $0.34^{*}$ & 0.09 & $0.35^{\star}$ & $0.29^{*}$ & $0.22^{\dagger}$ & $0.24^{\dagger}$ & $0.35^{*}$ & $0.57^{*}$ \\
\hline Fat mass (\%) & $0.36^{*}$ & 0.11 & $0.21^{\ddagger}$ & $0.38^{*}$ & 0.16 & 0.20 & $0.32^{\ddagger}$ & $0.55^{*}$ \\
\hline $\operatorname{VAT}\left(\mathrm{cm}^{2}\right)$ & $0.27^{*}$ & $0.22^{\ddagger}$ & $0.32^{*}$ & $0.18^{\dagger}$ & $0.26^{\dagger}$ & $0.23^{\dagger}$ & $0.36^{\star}$ & $0.32^{\ddagger}$ \\
\hline SAT $\left(\mathrm{cm}^{2}\right)$ & $0.26^{*}$ & 0.04 & $0.20^{\ddagger}$ & $0.37^{*}$ & 0.14 & 0.16 & $0.28^{\dagger}$ & $0.58^{*}$ \\
\hline Visceral/subcutaneous ratio & 0.12 & $0.19^{\ddagger}$ & $0.21^{\ddagger}$ & -0.04 & 0.13 & 0.10 & 0.15 & -0.20 \\
\hline HDL cholesterol (mmol/l) & $-0.16^{\dagger}$ & 0.08 & $-0.22^{\ddagger}$ & -0.02 & 0.04 & 0.03 & -0.21 & -0.07 \\
\hline Triglycerides $(\mathrm{mmol} / \mathrm{l})$ & 0.08 & 0.11 & $0.24^{*}$ & 0.09 & -0.18 & 0.15 & 0.11 & -0.11 \\
\hline Fasting glucose $(\mathrm{mmol} / \mathrm{l})$ & 0.03 & 0.09 & $0.31^{*}$ & 0.05 & -0.01 & 0.10 & $0.23^{\dagger}$ & 0.11 \\
\hline Fasting insulin (mU/l) & $0.18^{\dagger}$ & 0.13 & $0.38^{*}$ & $0.23^{\ddagger}$ & 0.05 & 0.18 & $0.34^{\ddagger}$ & 0.20 \\
\hline HOMA-IR & $0.17^{\dagger}$ & 0.13 & $0.41^{*}$ & $0.22^{\ddagger}$ & 0.10 & 0.17 & $0.44^{*}$ & $0.24^{\dagger}$ \\
\hline Leptin (ng/ml) & 0.11 & 0.11 & $0.23^{\star}$ & - & 0.13 & $0.31^{\dagger}$ & $0.36^{*}$ & - \\
\hline
\end{tabular}

${ }^{\star} P \leq 0.001 ;{ }^{\dagger} P \leq 0.05 ;{ }^{\ddagger} P \leq 0.01$.

VWF:Ag, von Willebrand factor antigen; PAI-1, plasminogen activator inhibitor-1; BMI, body mass index; VAT, visceral adipose tissue; SAT, subcutaneous adipose tissue; HDL, high density lipoprotein: HOMA-IR, homeostatic model assessment of insulin resistance. 


\section{Results}

\section{Relationship between leptin and fibrinogen, vWF:Ag and PAI-1}

Pearson correlation coefficient values for men and women are shown in Table 2. Leptin levels were not related to fibrinogen levels and a relationship between leptin and vWF:Ag was found only in men. However, leptin levels were found to be related to PAI-1 activity in both genders. In both women and men, the relationship between PAI-1 activity and leptin remained significant after correction for age and fat mass percentage $(r=0.18 ; P=0.016$ and $r=0.23$; $P=0.039$ respectively), age and VAT $(r=0.18$; $P=0.013$ and $r=0.25 ; P=0.025$ respectively), age and SAT $(r=0.15 ; P=0.032$ and $r=0.24 ; P=0.038)$, and age and HOMA-IR $(r=0.15 ; P=0.044$ and $r=0.29 ; P=0.010$ respectively). After simultaneous adjustment for age, fat mass percentage, and HOMAIR, the relationship was borderline significant in women $(r=0.15 ; P=0.049)$, but non-significant in men $(r=0.20 ; P=0.09)$, probably due to the lower number of subjects in the male subgroup. Again, after simultaneous adjustment for age, fat mass percentage, and VAT $(r=0.18 ; P=0.016)$ or SAT $(r=0.16$; $P=0.033)$, the relationship remained significant in women, and non-significant in men $(r=0.21$; $P=0.063$ and $r=0.22 ; P=0.062$ respectively). The relationship found between $\mathrm{vWF}: \mathrm{Ag}$ and leptin in men remained significant after adjustment for age and fat mass percentage $(r=0.24 ; P=0.024)$, age and VAT $(r=0.30 ; P=0.007)$, age and SAT $(r=0.26 ; P=0.02)$ and age and HOMA-IR $(r=0.32 ; P=0.004)$. After simultaneous adjustment for age, fat mass percentage and HOMA-IR $(r=0.24 ; P=0.04)$, VAT $(P=0.24$; $P=0.034)$ or SAT $(r=0.24 ; P=0.034)$, the relationship remained significant.

\section{Contribution of leptin versus VAT, SAT, and HOMA-IR in the variation of PAI-1 activity}

In order to elucidate the role of leptin versus VAT, SAT, and HOMA-IR in the variation of PAI-1 activity levels, we divided the female and male sample based on the median value of leptin and the median values of VAT, SAT, and HOMA-IR (Figs 1 and 2). In women, leptin and VAT, and leptin and HOMA-IR showed an independent effect on the variation of PAI-1 activity levels, while there was no effect of the interaction terms. In contrast, SAT or the interaction term leptin*SAT did not have an effect independent of leptin. In men, leptin did not contribute to the variation in PAI-1 activity levels, while the effect of VAT was borderline significant. While leptin did not show an effect, independent of SAT, the interaction term leptin*SAT did have a significant effect. The effect of leptin levels on the variation in PAI- 1 was dependent on HOMA-IR, while there was a significant effect of the interaction term leptin*HOMA-IR.

\section{Stepwise regression analyses}

In order to investigate whether leptin was an independent determinant of PAI-1 activity, we performed a stepwise regression analysis with PAI-1 activity as a dependent variable (Table 3 ). We only included factors that correlated with PAI- $1(r \geqq 0.20 ; P<0.05)$ and did not include variables expressing the same parameter (BMI versus fat mass percentage, fasting insulin and glucose versus HOMA-IR). Since waist circumference reflects the amount of VAT and SAT, we decided to include VAT and SAT in the first model and waist circumference in the second. In men and women, and in both models, HOMA-IR was the most important determinant of PAI-1 activity, but leptin was also an independent determinant (Table 3).
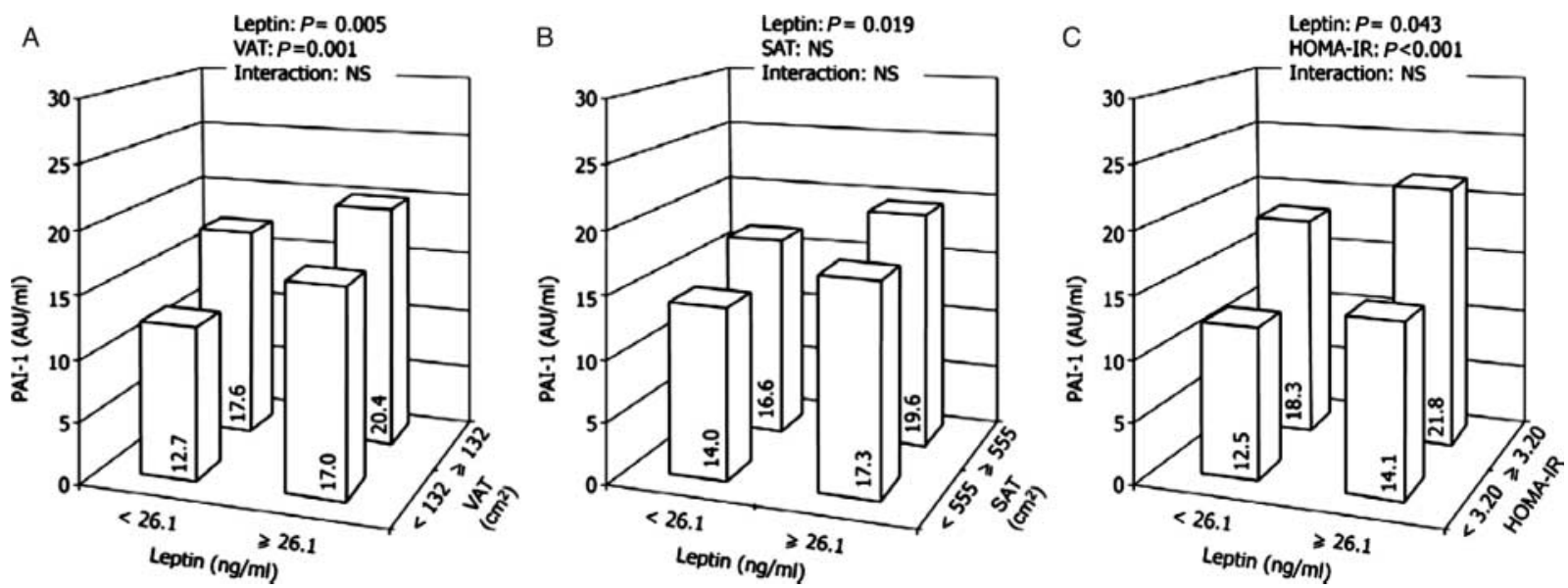

Figure 1 Influence of high and low levels of leptin combined with high and low levels of visceral adipose tissue (VAT), subcutaneous adipose tissue (SAT), and insulin resistance (HOMA-IR) on the variation in plasminogen activator inhibitor-1 (PAI-1) activity in women $(2 \times 2$ ANOVA). NS, Not significant. 

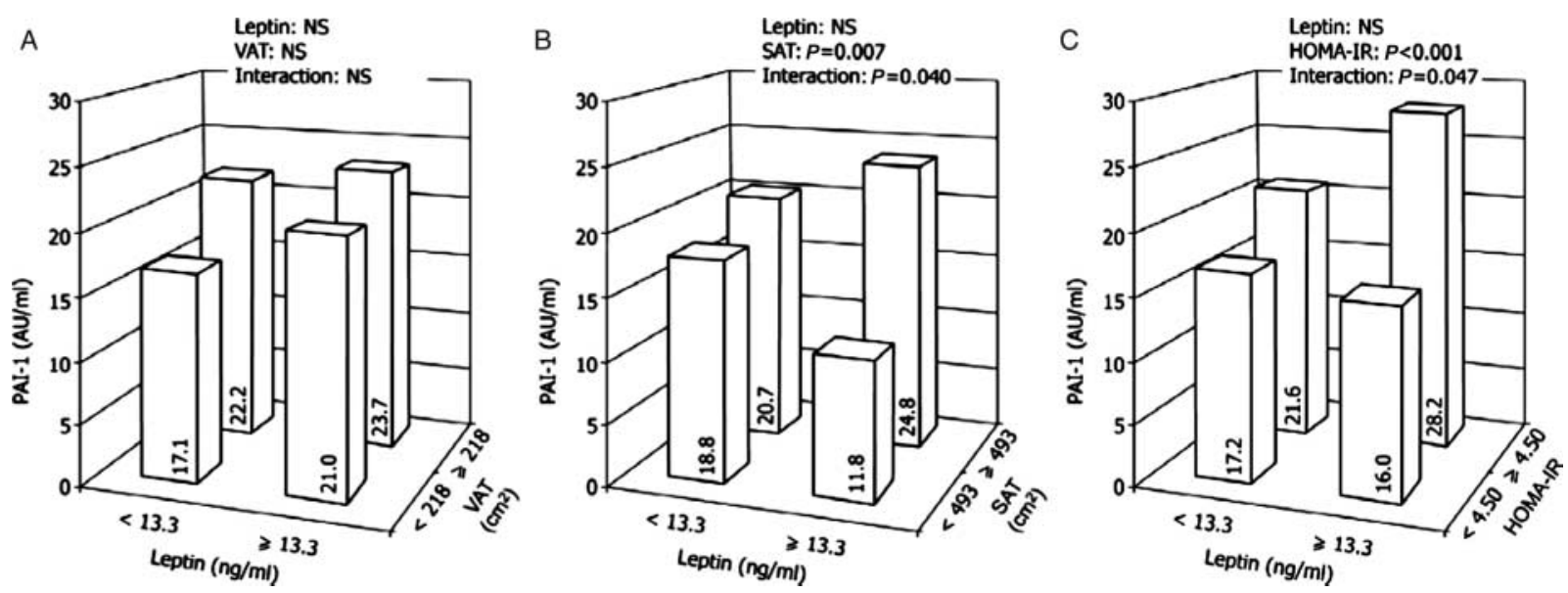

Figure 2 Influence of high and low levels of leptin combined with high and low levels of visceral adipose tissue (VAT), subcutaneous adipose tissue (SAT), and insulin resistance (HOMA-IR) on the variation in plasminogen activator inhibitor-1 (PAI-1) activity in men (2×2 ANOVA). NS, Not significant.

In the male subgroup, we performed a multiple regression analysis to investigate whether leptin was an independent determinant of vWF:Ag and included fat mass percentage, leptin and VAT as independent variables, showing leptin as the only independent determinant of vWF:Ag, although explaining only $8 \%$ of the variance in vWF:Ag levels (data not shown).

\section{Discussion}

In this study of overweight and obese non-diabetic women and men, we found leptin to be a positive determinant of PAI-1 activity, independent of age, fat mass percentage and HOMA-IR. Leptin was also an independent determinant of $\mathrm{vWF}: \mathrm{Ag}$ in men, while we did not find a relationship in women. We could not demonstrate a relationship between leptin and fibrinogen. Among studies investigating the potential mediators of the relationship between PAI-1 and leptin, we are, to the best of their knowledge, the first to study the influence of the exact amount of VAT versus SAT, as measured by CT-scan. Only two previous studies, finding a relationship between PAI-1 and leptin, investigated the influence of body fat distribution and found the relationship to be independent of (12) or dependent (19) on BMI or fat mass percentage and WHR used as a crude estimate of VAT. However, the latter study was performed in obese children, which could have influenced the results. Among all adult patients, multiple regression analysis showed leptin to be a determinant of PAI-1 activity in both sexes, independent of fat distribution estimates, VAT or SAT. Results from ANOVA confirm these results in women, but not in

Table 3 Multiple regression analyses with plasminogen activator inhibitor-1 (PAl-1) activity as dependent variable.

\begin{tabular}{|c|c|c|c|c|}
\hline & B & SEB & $r^{2}$ & $P$ value \\
\hline \multicolumn{5}{|c|}{ Women } \\
\hline 1. HOMA-IR & 13.348 & 2.416 & 0.17 & $<0.001$ \\
\hline 2. Leptin & 6.628 & 2.550 & 0.20 & 0.010 \\
\hline \multicolumn{5}{|c|}{ Model 2: fat mass percentage, waist, HDL cholesterol, triglycerides HOMA-IR, leptin } \\
\hline 1. HOMA-IR & 11.065 & 2.613 & 0.18 & $<0.001$ \\
\hline 2. Leptin & 6.061 & 2.608 & 0.20 & 0.021 \\
\hline 3. Waist & 0.087 & 0.043 & 0.21 & 0.045 \\
\hline Men & & & & \\
\hline \multicolumn{5}{|c|}{ Model 1: fat mass percentage, VAT, SAT, HOMA-IR, leptin } \\
\hline 1. HOMA-IR & 11.941 & 3.788 & 0.17 & 0.002 \\
\hline 2. VAT & 0.025 & 0.012 & 0.24 & 0.034 \\
\hline 3. Leptin & 0.188 & 0.088 & 0.27 & 0.037 \\
\hline \multicolumn{5}{|c|}{ Model 2: fat mass percentage, waist, HOMA-IR, leptin } \\
\hline 1. HOMA-IR & 13.712 & 3.819 & 0.17 & 0.001 \\
\hline 2. Leptin & 0.240 & 0.089 & 0.24 & 0.009 \\
\hline
\end{tabular}

VAT, visceral adipose tissue; SAT, subcutaneous adipose tissue; HDL, high density lipoprotein; HOMA-IR, homeostatic model assessment of insulin resistance. 
men. This gender effect, however, could be due to the lower number of men in the study sample. In vitro data have shown that the expression of leptin is higher in subcutaneous compared with omental adipose tissue $(9$, 10 ), while for PAI-1, this seems to be the other way round (27). In the female group, the subcutaneous to visceral ratio was much higher, making the subcutaneous fat depot the major source of leptin. The question, however, remains whether the relationship observed between leptin levels and PAI-1 is causal or not, and if it is, in which direction? In obesity, leptin produced almost exclusively from adipocytes (2), could trigger PAI-1 production from various cell types, such as adipocytes, endothelial cells, smooth muscle cells, hepatocytes, and/ or platelets (28). Indeed, leptin receptors have been found on hepatocytes (29), endothelial cells (30), and platelets (31). Surprisingly, a study in $o b / o b$ mice, a genetic animal model lacking leptin, showed increased levels of plasma PAI-1 activity (32), which is in contrast with the positive association we found between leptin and PAI-1 activity. Recently, a study in predominantly normal weight women investigated the effects of physiological leptin administration and found no effect on serum PAI-1 levels (33). However, it has been shown previously that mechanisms postulated from the studies using the $o b / o b$ mice (32) and lean individuals (33) cannot be extrapolated to obese humans showing increased leptin levels and (selective) leptin resistance (26). Next to a direct effect of leptin on PAI-1 expression, different indirect pathways linking leptin to PAI-1 activity in obesity could be put forward, such as the involvement of the sympathetic nervous system $(34,35)$, glucocorticoids $(36,37)$, inflammation (38), HOMA-IR, and/or body fat distribution $(39,11)$. In this study insulin resistance was found to be the major determinant of PAI-1 activity, although leptin levels seemed to relate to PAI-1 activity independent of insulin resistance. In the present study, we found an independent relationship between leptin and vWF:Ag in the male subgroup, while other studies in women or men did (14) or did not (13) find an association. In the study by Guagnano et al. (14), this relationship was also independent of body fat distribution, as measured by WHR. A specific leptin receptor $(\mathrm{Ob}-\mathrm{Rb})$ is expressed in human endothelial cells (30), which may link leptin expression to endothelial activation, leading to increased levels of the endothelialderived $\mathrm{vWF}$.

In this study, as previously found by others (19), we did not find an independent relationship between leptin levels and fibrinogen. Two other studies $(5,27)$, found an association between fibrinogen and leptin, which disappeared after adjustment for fat mass percentage or BMI. Only one study, in a small group of obese and nonobese men (13), found a relationship between fibrinogen and leptin independent of fat mass percentage.

It is clear that this study has some limitations. The authors do not have data on the regularity of the menstrual cycle of the pre-menopausal women and blood samples were not taken in the same phase of the menstrual cycle for each patient. Since gonadotropins have been shown to influence leptin (40) and some hemostatic and fibrinolytic factors (41), this could have influenced our results. In contrast to most other studies investigating the influence of smoking on hemostatic and fibrinolytic factors (42-44), we did not find significantly higher levels of these factors in smokers compared with non-smokers, which could be due to the low absolute number of smokers in both men and women. Leptin (45) and the hemostatic and fibrinolytic system (46) have been related to inflammation, and prolactin has been suggested to influence platelet aggregation (47) and fibrinolysis (48). However, in this study, adjusting for prolactin levels or leukocyte count as a marker of inflammation, did not influence the relationships found between leptin and fibrinogen, and vWF:Ag or PAI-1 (data not shown).

In conclusion, PAI-1 activity related to leptin levels independent of fat mass percentage, insulin resistance, and the amount of VAT and SAT; for VWF:Ag, this relationship was found only in men, and not in women, while we could not demonstrate a relationship with fibrinogen.

\section{References}

1 Eckel RH, Barouch WW \& Ershow AG. Report of the National Heart Lung, and blood Institute-National Institute of Diabetes and Digestive and Kidney Diseases Working Group on the pathophysiology of obesity-associated cardiovascular disease. Circulation 2002105 2923-2928.

2 Zhang Y, Proenca R, Maffei M, Barone M, Leopold L \& Friedman JM. Positional cloning of the mouse obese gene and its human homologue. Nature $1994372425-432$.

3 Alessi MC, Peiretti F, Morange P, Henry M, Nalbone G \& JuhanVague I. Production of plasminogen activator inhibitor 1 by human adipose tissue: possible link between visceral fat accumulation and vascular disease. Diabetes 199746 860-867.

4 Considine RV. Human leptin: an adipocyte hormone with weightregulatory and endocrine functions. Seminars in Vascular Medicine 20055 15-24.

5 Söderberg S, Olsson T, Eliasson M, Johnson O \& Ahren B. Plasma leptin levels are associated with abnormal fibrinolysis in men and postmenopausal women. Journal of Internal Medicine $1999 \mathbf{2 4 5}$ 533-543.

6 Wallace AM, McMahon AD, Packard CJ, Kelly A, Shepherd J, Gaw A \& Sattar N. Plasma leptin and the risk of cardiovascular disease in the west of Scotland coronary prevention study (WOSCOPS). Circulation $2001 \mathbf{1 0 4} 3052-3060$.

7 Couillard C, Lamarche B, Mauriege P, Cantin B, Dagenais GR, Moorjani S, Lupien PJ \& Després JP. Leptinemia is not a risk factor for ischemic heart disease in men Prospective results from the Quebec Cardiovascular Study. Diabetes Care 199821 782-786.

8 Ruige JB, Mertens I, Considine RV, Paelinck P \& Van Gaal LF. Opposite effects of insulin-like molecules and leptin in coronary heart disease of type 2 diabetes preliminary data. International Journal of Cardiology, 2005 (Epub ahead of print. doi: 10.1016/j.ijcard.2005.06.042).

9 Lefebvre AM, Laville M, Vega N, Riou JP, Van Gaal L, Auwerx J \& Vidal H. Depot-specific differences in adipose tissue gene expression in lean and obese subjects. Diabetes $1998 \mathbf{4 7} 98-103$. 
10 Van Harmelen V, Reynisdottir S, Eriksson P, Thorne A, Hoffstedt J. Lonnqvist F \& Arner P. Leptin secretion from subcutaneous and visceral adipose tissue in women. Diabetes 199847 913-917.

11 Mertens I \& Van Gaal LF. Obesity, haemostasis and the fibrinolytic system. Obesity Reviews 20023 85-101.

12 De Mitrio V, De Pergola G, Vettor R, Marino R, Sciaraffia M, Pagano C, Scaraggi FA, Di Lorenzo L \& Giorgino R. Plasma plasminogen activator inhibitor- 1 is associated with plasma leptin irrespective of body mass index, body fat mass, and plasma insulin and metabolic parameters in premenopausal women. Metabolism $1999 \mathbf{4 8}$ 960-964.

13 Gomez-Ambrosi J, Salvador J, Paramo JA, Orbe J, de Irala J, Diez-Caballero A, Gil MJ, Cienfuegos JA \& Fruhbeck G. Involvement of leptin in the association between percentage of body fat and cardiovascular risk factors. Clinical Biochemistry 200235 315-320.

14 Guagnano MT, Romano M, Falco A, Nutini M, Marinopiccoli M , Manigrasso MR, Basili S \& Davi G. Leptin increase is associated with markers of the hemostatic system in obese healthy women. Journal of Thrombosis and Haemostasis $2003 \mathbf{1}$ 2330-2334.

15 Wannamethee SG, Tchernova J, Whincup P, Lowe GD, Kelly A, Rumley A, Wallace AM \& Sattar N. Plasma leptin: associations with metabolic, inflammatory and haemostatic risk factors for cardiovascular disease. Atherosclerosis, 2006 (Epub ahead of print. doi: 10.1016/j.atherosclerosis.2006.04.012).

16 Sudi KM, Gallistl S, Weinhandl G, Muntean W \& Borkenstein MH. Relationship between plasminogen activator inhibitor- 1 antigen, leptin, and fat mass in obese children and adolescents. Metabolism 200049 890-895.

17 van Dielen FM, van't Veer C, Schols AM, Soeters PB, Buurman WA \& Greve JW. Increased leptin concentrations correlate with increased concentrations of inflammatory markers in morbidly obese individuals. International Journal of Obesity 200125 1759-1766.

18 Skurk T, van Harmelen V, Lee YM, Wirth A \& Hauner H. Relationship between IL-6, leptin and adiponectin and variables of fibrinolysis in overweight and obese hypertensive patients. Hormone and Metabolic Research 200234 659-663.

19 Valle M, Gascon F, Martos R, Bermudo F, Ceballos P \& Suanes A. Relationship between high plasma leptin concentrations and metabolic syndrome in obese pre-pubertal children. International Journal of Obesity 200327 13-18.

20 Gomez-Ambrosi J, Salvador J, Silva C, Pastor C, Rotellar F, Gil MJ, Cienfuegos JA \& Fruhbeck G. Increased cardiovascular risk markers in obesity are associated with body adiposity: role of leptin. Thrombosis and Haemostasis 200695 991-996.

21 Lukaski HC, Johnson PE, Bolonchuk WW \& Lykken GI. Assessment of fat-free mass using bioelectrical impedance measurements of the human body. American Journal of Clinical Nutrition 198541 810-817.

22 Deurenberg P, Weststrate JA \& Hautvast JG. Changes in fat-free mass during weight loss measured by bioelectrical impedance and by densitometry. American Journal of Clinical Nutrition 198949 33-36.

23 van der Kooy K \& Seidell JC. Techniques for the measurement of visceral fat: a practical guide. International Journal of Obesity 1993 17 187-196.

24 World Health Organization Definition, Diagnosis and Classification of Diabetes Mellitus and its Complications: Report of a WHO Consultation. Geneva 1999. WHO/NCD/NCS 99.2.

25 Matthews DR, Hosker JP, Rudenski AS, Naylor BA, Treacher DF \& Turner RC. Homeostasis model assessment: insulin resistance and beta-cell function from fasting plasma glucose and insulin concentrations in man. Diabetologia 198528 412-419.

26 Considine RV, Sinha MK. Heiman ML, Kriauciunas A, Stephens TW, Nyce MR, Ohannesian JP, Marco CC, McKee LJ, Bauer TL \& Caro J. Serum immunoreactive-leptin concentrations in normal-weight and obese humans. New England Journal of Medicine 1996334 292-295.

27 Bastelica D, Morange P, Berthet B, Borghi H, Lacroix O, Grino M, Juhan-Vague I \& Alessi MC. Stromal cells are the main plasminogen activator inhibitor-1-producing cells in human fat: evidence of differences between visceral and subcutaneous deposits. Arteriosclerosis Thrombosis and Vascular Biology 2002 22 173-178.

28 Binder BR, Christ G, Gruber F, Grubic N, Hufnagl P, Krebs M, Mihaly J \& Prager GW. Plasminogen activator inhibitor 1: physiological and pathophysiological roles. News in Physiological Sciences 200217 56-61.

29 Cohen P, Yang G, Yu X, Soukas AA, Wolfish CS, Friedman JM \& Li CK. Induction of leptin receptor expression in the liver by leptin and food deprivation. Biological Chemistry $2005 \mathbf{8 0}$ 10034-10039.

30 Maruyama I, Nakata M \& Yamaji K. Effect of leptin in platelet and endothelial cells. Obesity and arterial thrombosis. Annals of the New York Academy of Sciences 2000902 315-319.

31 Nakata M, Yada T, Soejima N \& Maruyama I. Leptin promotes aggregation of human platelets via the long form of its receptor. Diabetes 199948 426-429.

32 Samad F \& Loskutoff DJ. Tissue distribution and regulation of plasminogen activator inhibitor-1 in obese mice. Molecular Medicine $19962568-582$.

33 Canavan B, Salem RO, Schurgin S, Koutkia P, Lipinska I, Laposata M \& Grinspoon S. Effects of physiological leptin administration on markers of inflammation, platelet activation, and platelet aggregation during caloric deprivation. Journal of Clinical Endocrinology and Metabolism 200590 5779-5785.

34 Miskin R \& Abramovitz R. Enhancement of PAI-1 mRNA in cardiovascular cells after kainate injection is mediated through the sympathetic nervous system. Journal of Molecular and Cellular Cardiology 200538 715-722.

35 Ren J. Leptin and hyperleptinemia - from friend to foe for cardiovascular function. Journal of Endocrinology 2004 181 1-10.

36 Halleux CM, Servais I, Reul BA, Detry R \& Brichard SM. Multihormonal control of ob gene expression and leptin secretion from cultured human visceral adipose tissue: increased responsiveness to glucocorticoids in obesity. Journal of Clinical Endocrinology and Metabolism 199883 902-910.

37 Halleux CM, Declerck PJ, Tran SL, Detry R \& Brichard SM. Hormonal control of plasminogen activator inhibitor-1 gene expression and production in human adipose tissue: stimulation by glucocorticoids and inhibition by catecholamines. Journal of Clinical Endocrinology and Metabolism 199984 4097-4105.

38 Bullo M. Garcia-Lorda P. Megias I \& Salas-Salvado J. Systemic inflammation, adipose tissue tumor necrosis factor, and leptin expression. Obesity Research 200311 525-531.

39 Wauters M, Considine R, Löfgren A, Van Broeckhoven C, Van der Auwera JC, De Leeuw I \& Van Gaal L. Associations of leptin with body fat distribution and metabolic parameters in non-insulindependent diabetic patients: no effect of apolipoprotein $\mathrm{E}$ polymorphism. Metabolism 200049 724-730.

40 Wauters M, Considine RV \& Van Gaal LF. Human leptin: from an adipocyte hormone to an endocrine mediator. European Journal of Endocrinology. 2000143 293-311.

41 Ricci G, Cerneca F, Simeone R, Pozzobon C, Guarnieri S, Sartore A, Pregazzi R \& Guaschino S. Impact of highly purified urinary FSH and recombinant FSH on haemostasis: an open-label, randomized, controlled trial. Human Reproduction 200419 838-848.

42 Stec JJ, Silbershatz H, Tofler GH, Matheney TH, Sutherland P, Lipinska I, Massaro JM, Wilson PF, Muller JE \& D'Agostino RB, SR. Association of fibrinogen with cardiovascular risk factors and cardiovascular disease in the Framingham offspring population. Circulation 2000102 1634-1638.

43 Eliasson M, Asplund K, Evrin PE \& Lundblad D. Relationship of cigarette smoking and snuff dipping to plasma fibrinogen, fibrinolytic variables and serum insulin. The Northern Sweden MONICA Study. Atherosclerosis 1995113 41-53.

44 Cigolini M, Targher G, de Sandre G, Muggeo M \& Seidell JC. Plasma fibrinogen in relation to serum insulin, smoking habits and adipose tissue fatty acids in healthy men. European Journal of Clinical Investigation 199424 126-130. 
45 Otero M, Lago R, Lago F, Casanueva FF, Dieguez C, Gomez-Reino JJ \& Gualillo O. Leptin, from fat to inflammation: old questions and new insights. FEBS Letters 2005579 295-301.

46 Esmon CT. The interactions between inflammation and coagulation. British Journal of Haematology 2005131 417-430.

47 Wallaschofski H, Donne M, Eigenthaler M, Hentschel B, Faber R, Stepan H, Koksch M \& Lohmann T. PRL as a novel potent cofactor for platelet aggregation. Journal of Clinical Endocrinology and Metabolism 200186 5912-5919.
48 Liu YX, Peng XR, Liu HZ, Chen YJ \& Ny T. Prolactin regulation of tissue type plasminogen activator and plasminogen activator inhibitor type-I gene expression in eCG-primed rat granulosa cells in culture. Biology of Reproduction 199859 409-416.

Received 21 April 2006

Accepted 21 June 2006 